\title{
Volume models for Sal (Shorea robusta Gaertn.) in far-western Terai of Nepal
}

\begin{abstract}
T. Subedi ${ }^{1}$
Sal (Shorea robusta Gaertn.) is one of the most important commercial tree species in Nepal and far-western Terai is renowned for its forest. This study was carried out in far-western Terai to develop volume models of Sal at tree level using destructive sampling. Out of 99 sample trees, 81 data were used to develop the models and 18 data for validation of the selected models. Over bark stem diameters were measured at an interval of $0.5 \mathrm{~m}$ in lowermost three sections, at an interval of $1 \mathrm{~m}$ for one section and at an interval of $2 \mathrm{~m}$ in upper part of the trunk from the ground level. Smalian's formula was used to compute tree volume. Seven regression models were tested using $\mathrm{DBH}$ as a predictor variable. Cross validation of the independent data set was used to validate the selected models. The graphical analysis and fit statistics of the models were evaluated to select the best fit model. The selected model for total over bark stem volume is In $\mathrm{V}=-8.04674+2.26641 \mathrm{In} \mathrm{DBH}$ with $\mathrm{R}^{2}$ of $92 \%$ and standard error of 0.18 . Similarly, the selected models for over bark volume up to 10 and $20 \mathrm{~cm}$ top diameter have $\mathrm{R}^{2}$ of $82.41 \%$ and $79.97 \%$ and standard errors of 0.35 and 0.42 , respectively. The prediction error of the selected model was found to be less than $6 \%$. Forest managers can use the recommended model in estimation of timber volume of Sal in a particular forest area of this region for effective forest management.
\end{abstract}

Key words: Destructive sampling, far-western Terai, fit statistics, regression equation

$\mathrm{T}$ ree volume provides vital information in forest management for estimating current and future stock of forest. However, direct measurement of volume is a tedious and impractical in the field. Thus, models or mathematical functions are necessary to estimate the volume using some measurable variables such as height, diameter and form of the tree. Further, volume models have been used as one of the best means to estimate trees and stand volume and have played vital role in forest inventory, management and silvicultural research (Ozçelik et al., 2010).

In principle, height and diameter are measured in the routine forest measurement. However, height measurement is not always practical due to more time consuming and cost and possibility of being less accurate (Wagle and Sharma, 2011; Sharma and Pukkala, 1990b; Chaturvedi and Khanna, 1982). On one hand, the possibility of error increases more in the dense forest measuring tree height, on the other, DBH can be measured more easily and accurately with less time and cost. Further, volume table produced using a model with predictor variable DBH only is particularly useful for quick timber inventory. It can be tallied with species and only DBH (Sharma and Pukkala, 1990a; Chaturvedi and Khanna, 1982; Özçelik, 2008).

Department of Forest Research and Survey (DFRS) have been involved in producing various volume and biomass models (Sharma and Pukkala, 1990a; Laamanen et al, 1995, Tamrakar, 2000; Acharya et al., 2003) of tree species required for forest management for long time. The general volume tables of 21 tree species and two species groups were developed in 1990 using data collected in 1960s (Sharma and Pukkala, 1990a). During 1990s there were few studies on general volume and growth models of Sal, especially in central Bhabar forests of Nepal (Laamanen et al.,

\footnotetext{
${ }^{1}$ Department of Forest Research and Survey, Babarmahal, Kathmandu, Nepal

E-mail: ecothakur@yahoo.co.in
} 
1995). In addition to this, DFRS has developed biomass and volume models of some trees and bamboo species and some forest types. However, the diameter used in developing the models was $\leq$ $35 \mathrm{~cm}$ and the data were collected from thinning operation applied in trial plots may not represent the natural forest and again, the data were from only central part of the country (Acharya and Acharya, 2004; Acharya et al., 2003; Tamrakar, 2000; Pukkala et al, nd.).

$S$. robusta Gaertn., only one species found in Nepal of tropical family Dipterocarpaceae, is a multipurpose tree species. Sal is a valuable and important timber species for construction, and fuel wood. Sal seeds are used as raw material in industries and leaf used for making plates and as fodder for livestock (Jackson,1994). It is still most predominant species in the terai of Nepal (DFRS, 2014). It is found from Terai region to $1500 \mathrm{~m}$ but common up to $1000 \mathrm{~m}$. It occurs mostly in Terai, Siwalik and low land of hilly areas. In most areas, almost pure Sal forest can be found or in association with Terminalia alata. In some places, it grows along with broadleaved species. The Sal forests in the Terai (plain area) are mostly large and differ from hill Sal forest. In higher rainfall and moist areas, it is replaced by mixed forest. Dobremez (1976) listed nine types of Shorea forests, but Champion and Seth (1968) listed more than that, most of them are expected to be found in Nepal (cited by Jackson,1994).

The climate of far-western terai is drier than other parts of the country. Out of the total forest area of Kailali district, $32.16 \%$ is covered by Sal forest and $31.39 \%$ by Terai Mixed Hardwood (TMH) with Sal (DDC Kailali, 2015). The Sal forest in far-western Terai is similar with minor variations due to topographic and climatic similarity. Thus, DFRS, 2014 described as far-western forest clusters, which is different from those in other parts of the country because its climate is drier than other parts of the country. Therefore, the volume models based on one variable viz. DBH alone will be applicable.

In recent years, efforts have been made towards the scientific forest management in Nepal. However, there is lack of appropriate technical tool for volume and biomass estimation of timber. There is need for precise and site specific volume estimation equations using easily and accurately measurable independent variables of the trees. Realizing the situation, Department of Forests has called for preparing district wise local volume tables to estimate the timber quantity (DoF, 2014). Therefore, preparation of local volume equations of this species for the natural forest of far-western Terai is essential. The purpose of the study was to prepare local volume models of $S$. robusta for specific heights of tree trunk in far-western Terai.

\section{Materials and methods}

\section{Study area}

The study site is Balchaur area located at the eastern part of Kailali district and other sites such as Bani, Banka, Motipur, Gwalabari, Krishnapur, Basahan, Singapurur, etc. located at eastern and southern part of Kanchanpur district (Fig. 1).

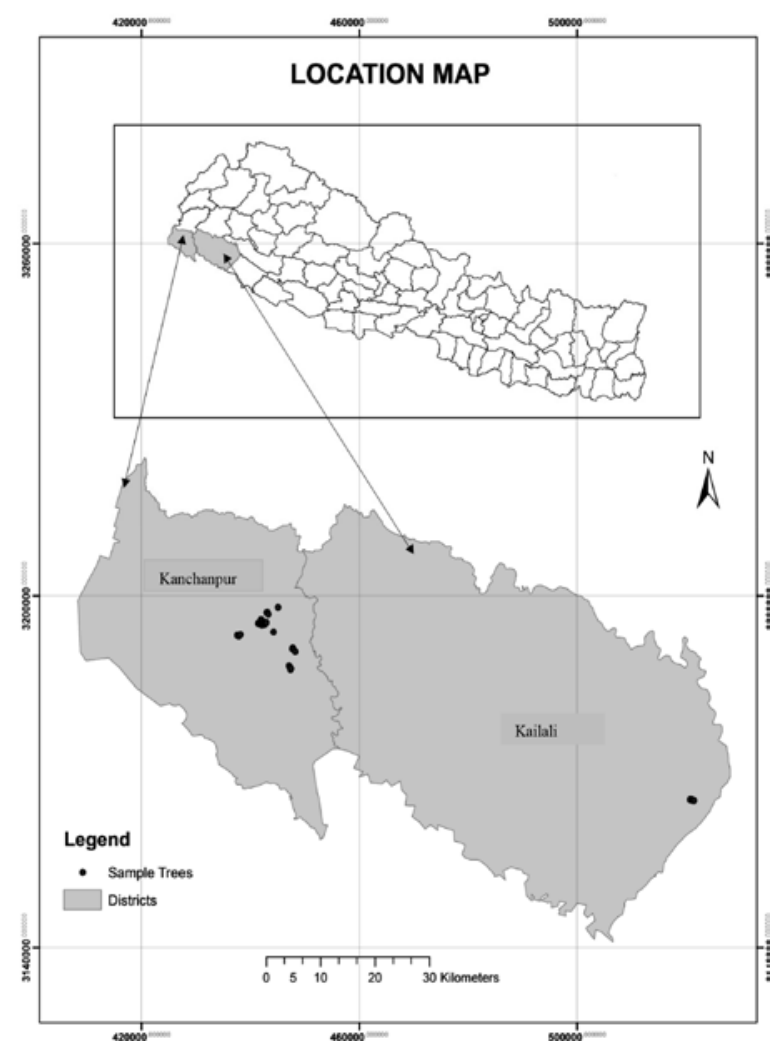

Fig 1: Map of the study area

These sites are in an altitudinal range of $109 \mathrm{~m}$ to $200 \mathrm{~m}$ above the mean sea level. Kailali district has an area of 3,235 sq. km, in which 40 per cent is covered by Terai (flat land) and 60 per cent by Chure hills. The total area of Kanchanpur district is 1610 sq. $\mathrm{km}$ in which 11.7 percent covered by Chure region, 55 percent is covered by forest and 
streams and $548.5 \mathrm{sq} . \mathrm{km}$. of wildlife reserves and its buffer zone area. The far-western Terai forest extends from the Karnali River in the east to the western border of Nepal. It covers 97,622 ha forest outside the protected area (DFRS, 2014). Sal forest, Terai Mixed Hardwood forest, Sal with Terai Mixed Hardwood forest and Khair-Sissoo forest are the dominant types of forest in this area (DFRS, 2014).

The southern parts of the districts consist of plain area with deep fine sandy loamy soil. The climate is generally sub-tropical. The precipitation and temperature from Dhangadhi and Mahendranagar stations represent eastern and western study sites, respectively. The data of precipitation and temperature in Dhangadhi are average figures of 25-years and 6-years, respectively. The data of precipitation and temperature in Mahendranagar are average figures of 10-years and 4-years, respectively. Average annual precipitation ranges from $1547 \mathrm{~mm}$ in Mahendranagar to $1725 \mathrm{~mm}$ in Dhangadhi. Average monthly temperature ranges from $23.7^{\circ} \mathrm{C}$ in Dhangadhi to $23.6^{\circ} \mathrm{C}$ in Mahendranagar. Absolute maximum temperature is $43.5^{\circ} \mathrm{C}$ whereas absolute minimum temperature is $2.0^{\circ} \mathrm{C}$ in Dhangadhi. Absolute maximum temperature is $43.0^{\circ} \mathrm{C}$ whereas absolute minimum temperature is $2.6^{\circ} \mathrm{C}$ in Mahendranagar. Dhangadhi annual autumn temperature is maximum $43^{\circ} \mathrm{C}$ to minimum $24^{\circ} \mathrm{C}$ and winter temperature is maximum $19^{\circ} \mathrm{C}$ to minimum $2^{\circ} \mathrm{C}$. In this way, average temperature is found as $30.5^{\circ}$ C. These climatic data taken from Department of Hydrology and Meteorology/Department of Irrigation, Hydrology and Meteorology are stated by Jackson (1994).

\section{Data collection}

According to the Forest Act (1993), plants above $30 \mathrm{~cm}$ diameter are regarded as tree and selected as samples for the study. The data of selected sample trees were collected above $30 \mathrm{~cm} \mathrm{DBH}$ to develop models particularly for estimation of Sal timber. The data were collected from the forests of far-western Terai. The trees above 30 $\mathrm{cm}$ diameter were divided into $10 \mathrm{~cm}$ diameter class up to $90 \mathrm{~cm}$ and one class above this. For each diameter class, at least 10 trees were selected for developing a model. The data were collected from different forest types, quality class, crown class and density to represent all the possible local minor variations of natural forest. The forest type, quality class, crown class and density were measured as in FRA (2010). The representative sample trees with respect to size (diameter) were chosen randomly among the available trees from all parts of the selected area. Twenty-one sample trees were selected from pure Sal forest, 23 from Sal-Asna mixed forest and 37 from Terai Mixed Hardwood forest to develop the model . The crown cover of these forests ranged from 30 to $85 \%$ having median of $60 \%$ crown cover. Similarly, the selected sample trees to develop the model were 67 from predominant, 12 from co-dominant and two from suppressed trees. In this way, 81 (32 from Kailali and 49 from Kanchanpur) sample trees were selected to develop the model. Similarly, 18 sample trees were selected from representative study area for validation of the models.

The basic characteristics of the site and sampled trees were recorded before felling the sample trees. After measuring DBH, trees were felled and over bark diameters were measured at an interval of $0.5 \mathrm{~m}$ in lowermost three sections, at an interval of $1 \mathrm{~m}$ for one section and at an interval of $2 \mathrm{~m}$ in upper part of the trunk (Sharma and Pukkala, 1990a; Eerikainen, 2001). Further the height of the sampled tree up to $10 \mathrm{~cm}$ and $20 \mathrm{~cm}$ over bark top diameters were recorded. The over bark diameters were measured by a diameter tape with an accuracy of $0.1 \mathrm{~cm}$. Sectional volume was calculated using Smalian's formula and then total volume and volume up to top 10 and $20 \mathrm{~cm}$ diameters were obtained by summing up sectional volumes (Laamanen et al.,1995, Segura and Kanninen, 2005 Özçelik, 2008, Ozçelik et al., 2010).

\section{Data structure and model development}

The average DBH and height of the sample trees were approximately $59 \mathrm{~cm}$ and $30 \mathrm{~m}$ (Table 1). The detailed descriptive statistics of 81 sample trees is given in table 1 . 
Table 1: Descriptive statistics of data of sample trees

\begin{tabular}{|l|c|c|c|c|c|c|}
\hline \multicolumn{1}{|c|}{ Variables } & $\begin{array}{c}\text { Number of } \\
\text { sample trees }\end{array}$ & Minimum & Median & Mean & Maximum & $\begin{array}{c}\text { Standard } \\
\text { deviation }\end{array}$ \\
\hline Total height $(\mathrm{m})$ & 81 & 19.00 & 30.05 & 29.91 & 41.20 & 5.05 \\
\hline DBH $(\mathrm{cm})$ & 81 & 30.10 & 57.50 & 59.21 & 108.50 & 16.86 \\
\hline Height diameter ratio & 81 & 0.38 & 0.50 & 0.53 & 0.76 & 0.10 \\
\hline Crown height $(\mathrm{m})$ & 72 & 3.40 & 12.20 & 12.39 & 23.30 & 5.28 \\
\hline Total volume $\left(\mathrm{m}^{3}\right)$ & 81 & 0.58 & 2.90 & 3.69 & 11.20 & 2.35 \\
\hline Volume up to $20 \mathrm{~cm}^{\left(\mathrm{m}^{3}\right)}$ & 81 & 0.38 & 2.80 & 3.59 & 11.14 & 2.36 \\
\hline Volume up to $10 \mathrm{~cm}\left(\mathrm{~m}^{3}\right)$ & 81 & 0.56 & 2.89 & 3.67 & 11.18 & 2.35 \\
\hline
\end{tabular}

The following different models were tested using R statistical software (R core Team, 2012).

$$
\begin{aligned}
& \mathrm{V}=\mathrm{a}+\mathrm{b} * \mathrm{D} \ldots \ldots \ldots \\
& \ln \mathrm{V}=\mathrm{a}+\mathrm{b} * \ln \mathrm{D} . . \\
& \mathrm{V}=\mathrm{a}+\mathrm{b} * \ln \mathrm{D} \ldots \ldots \\
& \ln \mathrm{V}=\mathrm{a}+\mathrm{b} * \mathrm{D} \ldots \ldots \\
& \mathrm{V}=\mathrm{a}+\mathrm{b} * \mathrm{D}_{2} \ldots \ldots \ldots \\
& \mathrm{V}=\mathrm{a}+\mathrm{b} * \mathrm{D}+\mathrm{c} * \mathrm{D}_{2} . \\
& \mathrm{V}=\mathrm{aDb} . \ldots \ldots \ldots \ldots \ldots
\end{aligned}
$$

Moreover, the following models were tested for predicting the volume of the proportion of sample tree in top $10 \mathrm{~cm}$ and top $20 \mathrm{~cm}$ over bark diameter (Sharma and Pukkala, 1990a; Laamanen et al., 1995).

$\ln \mathrm{V}_{1} / \mathrm{V}=\mathrm{a}+\mathrm{b} * \ln \mathrm{D}$

$\ln \mathrm{V}_{2} / \mathrm{Vt}=\mathrm{a}+\mathrm{b} * \ln \mathrm{D}$

where,

$\mathrm{a}, \mathrm{b}$ and $\mathrm{c}$ are parameters to be estimated,

$\mathrm{V}$ is total volume of tree,

$\mathrm{V}_{1}$ is volume beyond $10 \mathrm{~cm}$ top diameter,

$\mathrm{V}_{2}$ is volume between top 10 and $20 \mathrm{~cm}$ diameter,

$\mathrm{Vt}$ is volume up to $10 \mathrm{~cm}$ top diameter,

$\mathrm{DBH}$ is diameter at breast height and $\ln$ is the natural logarithm.

\section{Model selection and validation}

T-test and F-test were used for testing the significance of the parameters and whole equation, respectively. The best fit model was selected based on residual analysis (whether the model fulfilled regression assumption or not), and fit statistics (standard error, bias and coefficient of determination). The back transformation was done with bias correction by adding exp $\left(\mathrm{SE}^{2} / 2\right)$ to the intercept (Sprugel, 1983).

The method of cross validation technique was used (Hawkins, 1987; Kozak and Kozak, 2003). The models were evaluated by testing cross validation of separate data sets of 18 trees. The prediction statistics was estimated using following equation and percentage error were plotted against the explained variable (Hawkins,1987; Acharya et al., 2003; Ducey and Williams, 2011).

(bias $=\sum_{\mathrm{n}}^{\mathrm{i}}\left(\mathrm{yi}-\mathrm{y}^{\wedge}\right) / \mathrm{n}$

$\operatorname{RMSE}=\sqrt{ } \sum^{i}\left(y i-y^{\wedge}\right) /(n-1)$

Prediction error $=\left(\sum\right.$ actual volume $-\sum$ predicted volume) $/ \sum$ actual volume $\left.* 100\right) \ldots \ldots . .(x i i)$

\section{Results and discussion}

\section{Relationship between total volume and tree variables}

The relation of volume with both the height and DBH was found to be strong and positive (Fig. 2). The Pearson Correlation between total volume and DBH was found to be 0.9897. Similarly, the correlation between volume and height was found to be 0.8610 whereas it was
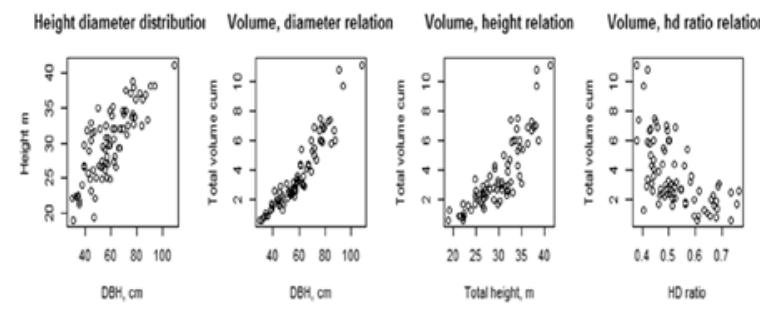

Fig 2: Relationship among different variables 
0.8011 between DBH and total height. Since, the total height has strong and positive relation with $\mathrm{DBH}$, the height adds very little effect on volume than that of the DBH alone.

\section{Total stem volume model}

Above mentioned models were fitted and checked both by graphically and numerically in order to identify the best predicted model. The fitted models were overlaid on the observed data (Fig. $3)$. In second graph, the observations are better distributed around the model throughout the DBH range. However, in all other figure, the models better capture the observation only in some part of the DBH range.

The seven different regression models as given above were fitted and checked both by graphically and numerically to test the best predicted model. The fitted models were overlaid on the observed data (Fig. 3).

Except the fifth and sixth models, the parameters of other five models are significant at $5 \%$ level of significance or even less. In general, all models fitted to the data well, as their good statistical fits in terms of $\mathrm{R}^{2}$ explained greater than $80 \%$ of variability (Table 2). There were variations in standard error of estimate (SEE) in different models and equation 2 has the lowest SEE which is less than 0.2.

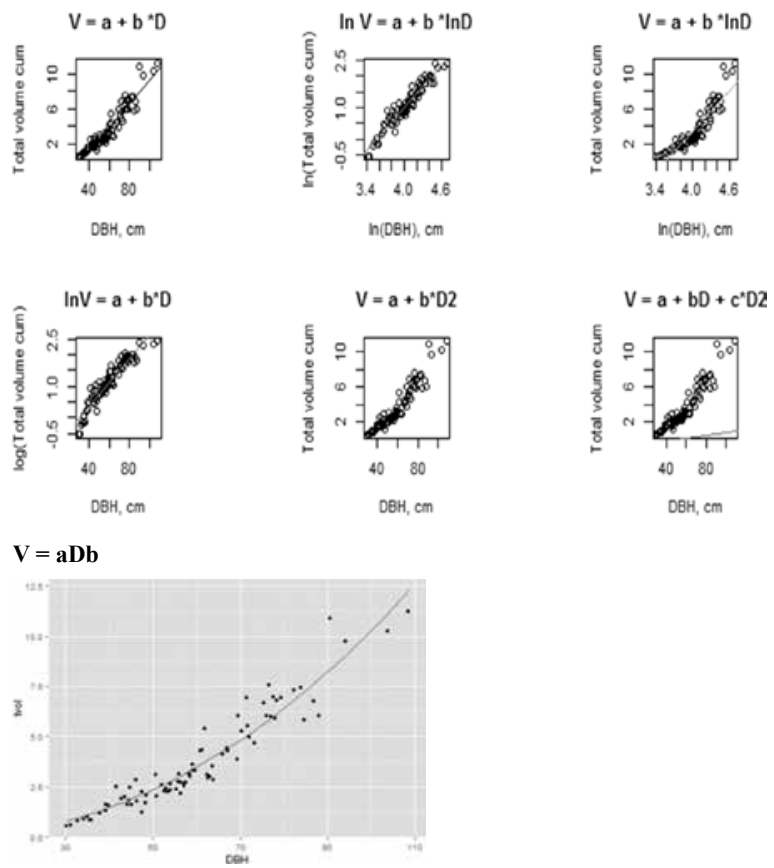

Fig. 3: Visualization of seven models

Table 2: Values of regression constants, std.error, $R^{2}$ with $t$ and $p$-values of tested models

\begin{tabular}{|c|c|c|c|c|c|c|c|c|}
\hline $\begin{array}{c}\text { Mo } \\
\text { del no. }\end{array}$ & $\begin{array}{l}\text { Para } \\
\text { meter }\end{array}$ & Estimate & $\begin{array}{l}\text { Standard } \\
\text { Error }\end{array}$ & t value & $\operatorname{Pr}(>|\mathbf{t}|)$ & $\begin{array}{c}\text { Sd. Error } \\
\text { of } \\
\text { Estimate }\end{array}$ & $\mathbf{R}^{2}$ & p-value \\
\hline \multirow[t]{2}{*}{1} & $\mathrm{a}$ & -4.3588 & 0.3291 & -13.2500 & $<2 \mathrm{e}-16^{* * *}$ & \multirow[t]{2}{*}{0.8053} & \multirow[t]{2}{*}{0.8915} & \multirow[t]{2}{*}{$<2.2 \mathrm{e}-16$} \\
\hline & $\mathrm{b}$ & 0.1360 & 0.0053 & 25.6600 & $<2 \mathrm{e}-16 * * *$ & & & \\
\hline \multirow[t]{2}{*}{2} & $\mathrm{a}$ & -8.0640 & 0.2930 & -27.5300 & $<2 \mathrm{e}-16 * * *$ & \multirow[t]{2}{*}{0.1859} & \multirow[t]{2}{*}{0.9249} & \multirow[t]{2}{*}{$<2.2 \mathrm{e}-16$} \\
\hline & $\mathrm{b}$ & 2.2664 & 0.0722 & 31.4100 & $<2 \mathrm{e}-16 * * *$ & & & \\
\hline \multirow[t]{2}{*}{3} & $\mathrm{a}$ & -27.2900 & 1.6610 & -16.4300 & $<2 \mathrm{e}-16 * * *$ & \multirow[t]{2}{*}{1.054} & \multirow[t]{2}{*}{0.8142} & \multirow[t]{2}{*}{$<2.2 \mathrm{e}-16$} \\
\hline & $\mathrm{b}$ & 7.6680 & 0.4090 & -18.7500 & $<2 \mathrm{e}-16 * * *$ & & & \\
\hline \multirow[t]{2}{*}{4} & $\mathrm{a}$ & -1.1329 & 0.0937 & -12.1000 & $<2 \mathrm{e}-16 * * *$ & \multirow[t]{2}{*}{0.2292} & \multirow[t]{2}{*}{0.8873} & \multirow[t]{2}{*}{$<2.2 \mathrm{e}-16$} \\
\hline & $\mathrm{b}$ & 0.0376 & 0.0015 & 24.9400 & $<2 \mathrm{e}-16 * * *$ & & & \\
\hline \multirow[t]{2}{*}{5} & $\mathrm{a}$ & -0.3144 & 0.1626 & -1.9330 & 0.568 & \multirow[t]{2}{*}{0.724} & \multirow[t]{2}{*}{0.9135} & \multirow[t]{2}{*}{$<2.2 \mathrm{e}-16$} \\
\hline & $\mathrm{b}$ & 0.0011 & 0.0000 & 28.8680 & $<2 \mathrm{e}-16 * * *$ & & & \\
\hline \multirow[t]{3}{*}{6} & $\mathrm{a}$ & -0.7848 & 0.8744 & -0.8970 & 0.372 & \multirow[t]{3}{*}{0.7272} & \multirow[t]{3}{*}{0.9137} & \multirow[t]{3}{*}{$<2.2 \mathrm{e}-16$} \\
\hline & $\mathrm{b}$ & 0.0154 & 0.0281 & 0.5480 & 0.586 & & & \\
\hline & $\mathrm{c}$ & 0.0009 & 0.0002 & 4.3460 & $4.14 \mathrm{e}-05^{* * *}$ & & & \\
\hline \multirow[t]{2}{*}{7} & $\mathrm{a}$ & 0.0006 & 0.0002 & 2.9250 & $0.00449 * *$ & 0.7306 & 0.8928 & $6.11 \mathrm{e}-06$ \\
\hline & $\mathrm{b}$ & 2.1144 & 0.0786 & 26.8970 & $<2 \mathrm{e}-16^{* * * *}$ & & & $\begin{array}{c}\text { (converge } \\
\text { nce } \\
\text { tolerance) }\end{array}$ \\
\hline
\end{tabular}

Note: $* *$ shows significant at $95 \%$ and $* * *$ shows significant at $99 \%$ confidence level 
In the past, similar models were tested for different species (Hawkins, 1987; DFRS, 2006). Laamanen et al. (1995) developed a general volume model with $\mathrm{R}^{2}$ of $97.1 \%$ and standard error of estimate of 0.13 for Adabhar, Bara district. The model developed for Sal by Sharma and Pukkala (1990) for producing general volume table has $\mathrm{R}^{2}$ of $98.3 \%$ and standard error of estimate of 0.13 and it is widely used. In both cases, DBH and height were used as predictor variables but in this study only DBH was used as a predictor variable, which alone explained $92.5 \%$ variation of the observed tree volume. Lower $\mathrm{R}^{2}$ value in this study may be due to the use of single predictor variable, $\mathrm{DBH}$. SEE is greater in one explained variable than two variables (Pukkala et al. n.d.). Other similar models were also developed in the past but their statistics of fit was not mentioned (Acharya et al., 2003).

The residuals of all models were analyzed. Due to the brevity of space, only graphs of the most suitable model (M2) were presented in figure 4. It is important to note that only model 2 showed homoscadascity and normality of residual distribution. The curve of the residuals was not seen sharply decrease or increase in the selected model. Similar trend was found for standardized residuals. Three outliers were found in which two outliers had underestimated and one outlier had overestimated values. The outlier samples were identified and analyzed. Though, removal of outliers improves the model reliability but they were not removed so as to represent the data from all parts of the study area.
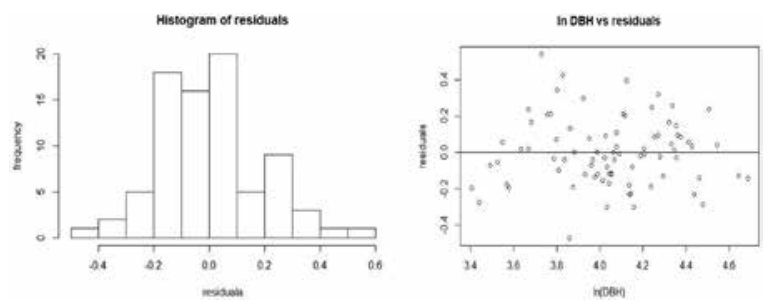

Fig. 4: Histogram of residuals and residuals versus Ln (DBH)

Table 3: Values of regression constants, $R^{2}$ and standard error of the models

\begin{tabular}{|c|c|c|c|c|c|c|}
\hline Model no. & Model & a & b & $\mathbf{R}^{2}$ & SEE & n \\
\hline 8 & $\ln \left(\mathrm{V}_{1} / \mathrm{V}\right)=\mathrm{a}+\mathrm{b} * \ln \mathrm{D}$ & 5.0445 & -2.6094 & 0.8241 & 0.3469 & 81 \\
\hline 9 & $\ln \left(\mathrm{V}_{2} / \mathrm{Vt}\right)=\mathrm{a}+\mathrm{b} * \ln \mathrm{D}$ & 8.221 & -2.954 & 0.7997 & 0.4253 & 81 \\
\hline
\end{tabular}

\section{Over bark stem volume up to top $10 \mathrm{~cm}$ and top $20 \mathrm{~cm}$ top diameter}

The distribution of ratios (M8 and M9) against its predictor variable clearly indicates that the data were distributed negative exponentially (Fig. 5). Hence the models with both side logarithms were used as in the past in similar cases (Sharma and Pukkala, 1990a; Laamanen et al., 1995).

In this case, only logarithmic model was tested as used in similar past studies (Sharma and Pukkala, 1990a; Laamanen et al., 1995). All the parameters of both models were significant (Table 3 ).

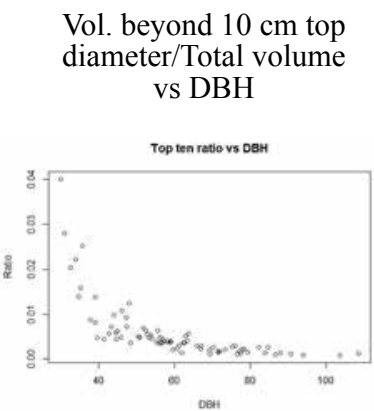

Volume between $10 \mathrm{~cm}$ to $20 \mathrm{~cm}$ top diameter/ Volume up to $10 \mathrm{~cm}$ top diameter vs DBH

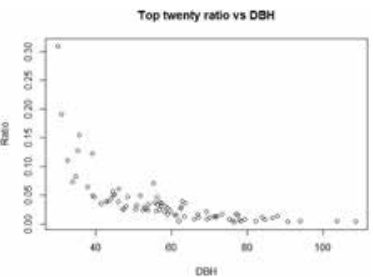

Fig. 5: Volume ratio of top 10 and $20 \mathrm{~cm}$ diameter vs. DBH

In comparison to total stem volume equation, the $\mathrm{R}^{2}$ values of both equations were lower, while standard error of estimates was higher. It may be due to error accumulation from total volume model. Sharma and Pukkala (1990a) reported 78.9 and $74.1 \mathrm{R}^{2}$ values for the ratio of top 10 and

$20 \mathrm{~cm}$ over bark diameter, respectively. Similarly their standard error of estimates was 0.51 for both the equations. These two models were better than Sharma and Pukkala (1990a) in terms of $\mathrm{R}^{2}$ and SEE (Table 3). However, the fit statistics reported by Laamanen et al. (1995) was better than that of the study. 
Table 4: Prediction statistics of the models

\begin{tabular}{|l|l|l|l|}
\hline Model & RMSE & Bias & Prediction error (\%) \\
\hline Total volume over bark & 0.3958158 & 0.1836834 & 5.812 \\
\hline Volume up to 10 cm over bark & 0.395469 & 0.1827535 & 5.809 \\
\hline Volume up to 20 cm over bark & 0.4009819 & 0.1759837 & 5.769 \\
\hline
\end{tabular}

The residuals of both models (M8 and M9) were found to be satisfactory and they were distributed evenly without any trend, so these models can be recommended. The residuals against DBH are shown in figure 6 .
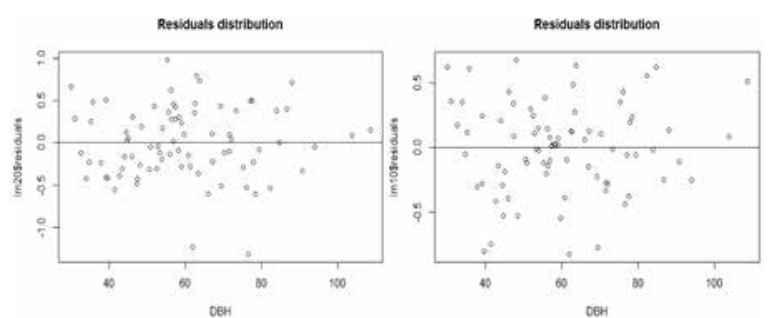

Fig. 6: Residuals vs. DBH in two models

\section{Model validation}

The definition and method of validation among the researchers were not found uniform (Kozak and Kozak, 2003; Bellocchi et al., 2010). Most of them considered components of fit statistics and graphical inspection for validation (Kozak and Kozak, 2003; Bellocchi et al., 2010). In addition to the analysis of fit statistics, Meehl et al. (2005) compared different models, which are used for similar purposes. Vanclay (1994) calculated the prediction statistics of independent data sets for model validation. Iles (2003) strongly recommended for checking few independent trees to measure accuracy of the volume table (cited by Ducey and Williams, 2011). Therefore, for validation of these equations, in addition to compare different equations, fit statistics and graphical inspection, the prediction statistics of 18 trees were analyzed.

The bias, RMSE and prediction error of models for total volume, and volume up to 10 and 20 $\mathrm{cm}$ diameter are almost similar (Table 4). The equation for total volume over bark was biased to $0.18 \mathrm{~m}^{3}$ with RMSE of nearly $0.4 \mathrm{~m}^{3}$, which is acceptable since validation data sets were fewer than modeled data, resulting losses of the information (Kozak and Kozak, 2003). Moreover, Hawkins (1987) recommended that the overall prediction error should be within 10 to $15 \%$ of the actual value. In this study, the prediction errors of selected model was found to be within $6 \%$ and were lower than that of Acharya et al. (2003). But some statisticians argue that due to fewer validations data sets rather than modeled data validation losses the information (Kozak and Kozak, 2003).

The predicted values of all suggested models were plotted against the actual values of test data sets (Fig. 7). There is slightly underestimation of volume mainly in large-sized trees (Fig. 7).

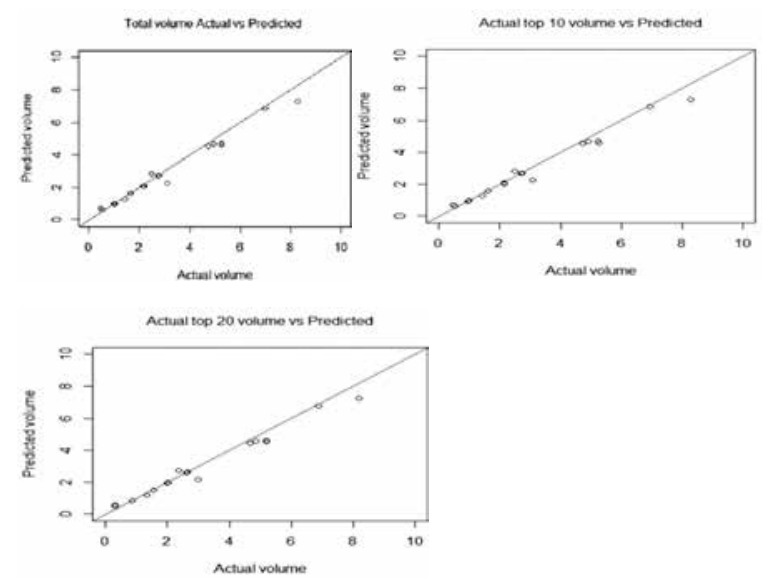

Fig. 7: Predicted versus actual volume

The individual error of test data set was evaluated by plotting against the diameter (Fig. 8). The overall prediction errors of all models were within limit but the error percentage of individual trees was a bit high in some cases. The models consistently underestimated volume of trees over the range of DBH (Fig. 8).
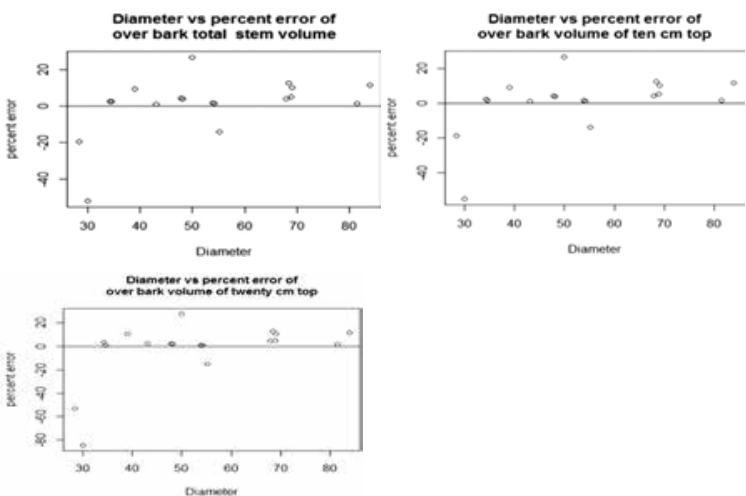

Fig. 8: Percent error vs. DBH of individual tested tree 


\section{Conclusion}

Among the tested seven models, the recommended logarithmic model has the smallest RMSE and bias, and higher $\mathrm{R}^{2}$. The model for total stem volume is $\ln \mathrm{V}=8.04674+2.26641 \ln \mathrm{DBH}$. The models for ratio of volume beyond $10 \mathrm{~cm}$ top diameter to total stem volume is $\ln \left(\mathrm{V}_{1} / \mathrm{V}\right)$ $=5.0618-2.6094 * \ln \mathrm{DBH}$ and ratio of volume between $10 \mathrm{~cm}$ and $20 \mathrm{~cm}$ diameter to volume up to $10 \mathrm{~cm}$ top diameter is $\ln \left(\mathrm{V}_{2} / \mathrm{Vt}\right)=8.31144$ - 2.954* $\ln (\mathrm{DBH})$. This study recommends for application of the equations within the range of sample data. Since, the samples are site specific, the models should be used cautiously in other places of Nepal after validating the models.

\section{Acknowledgements}

I highly acknowledge to Dr. Binaya Pasakhala for linguistic improvement and valuable comments. I also want to thank Mr. Kiran Kumar Pokharel for inspiring me to write this article.

\section{References}

Acharya, K. P. and Acharya, B. 2004. Early Growth Performance of Natural Sal (Shorea robudta) Dorest in Central Nepal. Department of Forest Research and Survey, Kathmandu, Nepal.

Acharya, K.P., Regmi, R. and Achrya, B. 2003. Biomass and Volume Tables for Terai Sal (Shorea robusta) Forest of Nepal. Department of Forest Research and Survey, Forest Research Leaflet No. 15.

Bellocchi, Gianni, Rivington, Mike, Donatelli, Marcello and Matthews, Keith. 2010. Validation of biophysical models: issues and methodologies. A review. Agronomy for Sustainable Development 30 (1): 109130

Champion, H. G. and Seth, S. K. 1968. A Revised Survey of the Forest Types of India. Manager of Publications, Delhi, India.

Chaturbedi A.N. and Khanna L.S. 1982. Forest Mensuration; International Book Distributors, Dehra Dun, India.

DoF. 2014. Commitments Paper; Fifth National
Meeting of District Forest Officers, Department of Forests (DoF), Kathmandu, Nepal.

DFRS.2006. Local Volume Tables for Major Tree Species in Dhaulagiri Area Department of Forest Research and Survey (DFRS), District Forest Offices: Parbat, Baglung and Myagdi, Livelihoods and Forestry Programme, Dhaulagiri Area.

DFRS. 2014. Terai Forests of Nepal. Forest Resource Assessment Nepal Project, Department of Forest Research and Survey, Kathmandu, Nepal.

DDC Kailali. 2015. District Profile: Periodic District Development Plan (Fiscal Year 2072/073 - 2076/077), District Development Committee, Kailali.

Dobremez, J. F.1976. Le Nepal, Ecologie et Biogeographie. CNRS, Paris, France.

Ducey, M. J. and Williams, M.S. 2011: Comparison of Hossfeld's method and two modern methods of volume estimation of standing trees. Western Journal of Applied Forestry 26 (1):19-23.

Eerikainen, Kalle. 2001. Stem volume models with random coefficients for Pinus kesiya in Tanzania, Zambia, and Zimbabwe. Canadian Journal of Forest Research 31 (5): $879-888$

FRA. 2010. Field Manual for Inventory Data Collection. Forest Resource Assessment Project, Kathmandu, Nepal. Unpublished.

Hawkins, Thomas. 1987. Biomass and Volume Tables for Eucalyptus camuldulensis, Dalargia sissoo, Acacia auriculiformis and Cassia siamea in the Central BhabarTerai of Nepal. Oxford Forestry Institute, Department of Plant Sciences, The UK.

Iles, (2003); A Sampler of Inventory Topics.: Kim Iles \& Associates Nanaimo, BC, Canada.

Jackson J. K.1994. Manual of Afforestation in Nepal. Volume 2. Forest Research and Survey Center, Kathmandu, Nepal. 
Kozak, Antal and Kozak, Robert. 2003. Does cross validation provide additional information in the evaluation of regression models. Canadian Journal of Forestry Research $\mathbf{3 3}$ (6): 976-987.

Laamanen, R., Joshi, M. R. and Sharma, S.P. 1995. Biomass and Volume Models for Sal in the Central Terai of Nepal. FRISP Project Paper No.7 Kathmandu, Nepal.

Özçelik, R. 2008. Comparison of formulae for estimating tree bole volumes of Pinus sylvestris . Scandinavian Journal of Forest Research 23 (5):412-418.

Ozçelik, R., Diamantopoulou, M. J., Brooks, J. R. and Wiant Jr., H.V. 2010. Estimating tree bole volume using artificial neural network models for four species in Turkey. Journal of Environmental Management 91 (3):742-753.

Pukkala, T., Sharma, E. R. and Rajbhandari, M. D. A Guide to Biomass Modeling for Forest Inventory in Nepal. Forest Survey and Statistics Division, Publication No. 51.

R Core Team. 2012. A language and environment for statistical computing. R Foundation for Statistical Computing, Vienna, Austria. ISBN 3-900051-07-0, URL http://www.Rproject.org/

Segura, M. and Kanninen, M., 2005. Allometric models for tree volume and total aboveground biomass. Biotropica 37 (1) : 2-8.

Sharma, E. R. and Pukkala, T. 1990a. Volume Equations and Biomass Prediction of Forest Trees of Nepal. Publication number 47. Ministry of Forests and Soil Conservation, Forest Survey and Statistics Division, Babarmahal, Kathmandu, Nepal.
Sharma, E. R. and Pukkala, T., 1990b: Volume Tables for Forest Trees of Nepal. Ministry of Forests and Soil Conservation, Forest Survey and Statistics Division, Babarmahal, Kathmandu, Nepal.

Publication number 48. Ministry of Forests and Soil Conservation, Forest Survey and Statistics Division, Babarmahal, Kathmandu, Nepal.

Sprugel, D.G. 1983. Corrected for bias in logtransformed allometric equations: Ecology 64 (1): 209-210.

Tamrakar, P. R. 2000. Biomass and Volume Table with Species Description for Community Forest Management, His majesty's Government of Nepal, Ministry of Forests and Soil Conservation, Natural Resources Management Sector Assistant Programme (NARMSAP), Tree Improvement and Silvicultural Component, Nepal.

Vanclay, J. K. 1994. Modelling Forest Growth and Yield. Application to Mixed Tropical Forest. CAB International, Oxon, UK.

Wagle, B. H. and Sharma, R. P. 2011. Modelling height-diameter relationship for Pinus wallichiana trees for Lete and Kunjo of Mustang district. Banko Janakari 21 (2): 13-23. 